\title{
LETTERS
}

\section{Unintended consequences of focusing on accommodations and supports as barriers for medical trainees with disabilities}

CMAJ is to be commended for calling attention to gaps in the provision of accommodations for trainees with disabilities. ${ }^{1}$ One topic not mentioned in its recent news report is provision of accommodations on the Medical College Admissions Test (MCAT), which serves as a major bottleneck in the medical education pipeline for persons with disabilities. Without accommodations (usually 50\% extra time), the MCAT could selectively eliminate many otherwise qualified individuals with attention-deficit/hyperactivity disorder, specific learning disorders and other disabilities from the medical profession altogether.

Yet we have no up-to-date or publicly available data available on the provision of accommodations for taking MCAT. In $2006,{ }^{2}$ Rajaram reported that one-third of those who apply for extra time on the MCAT (presumably all have documented disabilities) are not approved. It would be useful to know what percentage of those who apply for at least 50\% extra time on the MCAT receive it without a letter from an attorney or a court order.

There are also some possible unintended consequences of focusing on one limiting aspect for trainees with disabilities (lack of accommodations) to the exclusion of another (avoiding discrimination against trainees with real or suspected physical and mental disorders or disabilities). ${ }^{3}$ It may reinforce stereotypes that these trainees are economically burdensome and demand special treatment. Yet many trainees with these conditions or disabilities just want to be treated the same as everyone else. They do not want to be the target of physician impairment policies, prohibited medical inquiries and unwarranted negative attention within the biomedical literature. ${ }^{3-5}$ Academic medical journals are still framing burnout, mental disorders and disabilities as meaningful causes of medical errors and preventable adverse events in a way that simply does not accord with the available evidence. ${ }^{4}$

Continuing to neglect these barriers and focus disproportionately on accommodations will not lead to further inclusion of these learners.

\section{Nicholas D. Lawson MD}

Former psychiatry resident and incoming law student, Georgetown University Law Center, Washington, DC

- Cite as: CMAJ 2018 October 9;190:

E1213. doi: 10.1503/cmaj.70017

\section{References}

1. Vogel L. Major gaps in supports for medical trainees with disabilities. CMAJ 2018;190:E632-3.

2. Rajaram S. Cornerstone responds to the needs of disabled students. Student Life [Washington (DC)]. Available: www.studlife.com/archives/ News/2006/11/29/Cornerstonerespondstothe needsofdisabledstudents/ (accessed 2018 May 28).

3. Lawson ND. Structural stigma and discrimination against medical students and residents with suspected mental disorders [oral presentation]. In: Overcoming barriers in minds and society. Proceedings from the 8th International Together Against Stigma Conference; 2017 Sept. 20-22; Copenhagen, Denmark. Available: www.agains tstigma2017.com/images/Presentations/OR-3 -Structural-stigma-and-discrimination-against -medical-students-and-residents.pdf (accessed 2018 May 28).

4. Lawson ND, Boyd JW. Do state physician health programs encourage referrals that violate the Americans with Disabilities Act? Int J Law Psychiatry 2018;56:65-70.

5. Lawson ND, Kalet AL. The administrative psychiatric evaluation. J Grad Med Educ 2016;8:14-7.

Competing interests: None declared. 